\title{
Biodegradation of Polyurethane Derived from Castor Oil
}

\author{
José M. Cangemi \\ Instituto de Ensino Superior das Faculdades COC, Ribeirão Preto/SP \\ Antonia M. dos Santos \\ Departamento de Bioquímica e Microbiologia, UNESP, Rio Claro/SP
}

\author{
Salvador C. Neto, Gilberto O. Chierice \\ Instituto de Química de São Carlos, USP
}

\begin{abstract}
The aim of this research was to study the biodegradation of a polymer derived from castor oil, which is a renewable, natural material that is a practical alternative for the replacement of traditional polyurethane foams. Due to its molecular structure, which contains polyester segments derived from vegetable oil, the polymeric surface is susceptible to microorganism attack. This study tested the biological degrading agent that was in contact with the microorganisms resulting from microbiological grease degrading agents, when foam was inoculated. Solid-media agar-plate tests were conducted for their potential to evaluate the biodegradation of polymeric particles by specific strains of microorganisms during 216 hours. The growth rate was defined. This technique provides a way of distinguishing the degradation abilities of microorganisms from the degradability of materials.
\end{abstract}

Keywords: Biodegradation, polyurethane, castor oil, polyester, microorganisms.

\section{Introduction}

Due to the growth in residues that pollute the environment, the use of synthetic polymers has posed great concern. People are looking for biodegradable products. The use of plastics is growing because new and numerous applications are frequently emerging. Several factors are responsible for this evolution and cost and durability are among the most important of these. U.S. statistics show that approximately 160 million tons of solid residues are discarded annually in the environment, of which 6 to $7 \%$ are plastic residues, representing approximately $30 \%$ of the total quantity ${ }^{[1]}$.

Biodegradation or biological degradation consists of those processes resulting from the attack of a determined compound or live organism, for example bacteria, fungi, insects and rodents. However, this term is usually used only for degradation caused by microorganisms ${ }^{[2]}$. Plastics biodegradation can be profoundly affected by the conditions of the environment, the presence of additives in its composition and the kind of polymer. The action of microorganisms in polymeric materials can occur in three different forms ${ }^{[3]}$ :

- A biophysical effect, in which cellular growth can be caused by the loss of mechanical resistance in polymers;

- A biochemical effect, in which substances produced by microorganisms can act on the polymers; and

- A direct enzymatic action, in which microbial enzymes attack the components of plastic products, promoting oxidative breaks in the polymeric chain.
One of the polymers that has been used most frequently in recent years in many kinds of industries, is polyurethane foam. Polyurethanes (PU) were developed by Otto Bayer in 1937, and became a fantastic success story that is now a billion dollar business today. The market for PU's, started in the 30 seconds, reached 8.5 million tons of annual consumption by 2000 , and is expected to reach 9.5 million tons in 2002, and 10.8 million tons in 2004. Nowadays, PUs are the sixth most sold plastic in the world at about $6 \%$ of the market ${ }^{[4]}$. These foams are generally produced from petroleum derivatives, which are non-renewable raw materials that further generate non-biodegradable products.

After years of polyurethane production, studies have now begun to research its susceptibility to biodegradation. Darby \& $\operatorname{Kaplan}^{[5]}$ were the first to report degradation of PUs by fungi and their results indicated that polyester-type PUs were more biodegradable than polyether-type PUs. Since then, a great number of fungi and bacteria have been isolated and identified for their capacity to degrade polyester type PUs.

Huang et al. ${ }^{[6]}$ synthesized polyurethanes derived from the poly-caprolactone diol, in an attempt to produce a PU for medical applications. During this research study, various PUs containing various sizes of polyester units were synthesized. These polymers were submitted to biodegradation by axion enzymes and two species of fungi. The enzyme and fungi degraded the PUs, and the most notable result was the greater biodegradation in PUs with longer polyester chains. 
Nakajima-Kambe et al. ${ }^{[7]}$ isolated and characterized the bacteria Comamonas acidovorans, which utilizes polyester polyurethane as its only source of carbon and nitrogen. What stands out in this study is the fact that the bacteria did not degrade polyester-type PU. The authors also stated that the possible products of degradation would be adipic acid and diethylene glycol.

El-Sayed et al. ${ }^{[8]}$ tested the growth of various species of bacteria in PU-based paint for military aircraft. The researchers isolated Acinetobacter calcoaceticus, two species of Pseudomonas, Pseudomonas cepacia, and Arthrobacter globiformis. In addition to this, the U.S. Navy supplied the following strains of microrganisms: A. calcoaceticus, Pseudomonas aeruginosa and Pseudomonas putida. With the exception of Pseudomonas cepacia, all the microrganisms were capable of degrading polyurethane paint by utilizing it as its only source of carbon and energy.

Kim \& $\mathrm{Kim}^{[9]}$ investigated the biodegradation of diverse polyester type polyurethanes of different chemical structures. The stages of biodegradation were identified by two techniques: hydrolysis in $\mathrm{NaOH}$ solution and enzymatic degradation by lipase and composting. The authors concluded from the results that the rate of biodegradation increased in accordance with the diisocyanates utilized: $\mathrm{MDI}<\mathrm{H}_{12} \mathrm{MDI}<\mathrm{HDI}$. The PU composed of aliphatic diisocyanates demonstrated a greater rate of biodegradation than the PU composed of aromatic diisocyanates. When the polyol used was polyhexamethyleneadipate diol of polycaprolactone diol, the polyurethane obtained a higher rate of biodegradation in the composting condition.

Nakajima-Kambe et al. ${ }^{[10]}$ conducted a study of the metabolites produced from the degradation of polyester PU by the microorganism Comamonas acidovorans. Analysis of gaseous chromatography and mass spectrometry revealed the presence of diethylene glycol, trimethlypropane and adipic acid among the metabolites. In the author's analysis, these metabolites were derived from the polyester segments of $\mathrm{PU}$, the result of hydrolytic separation of the ester chains. Another metabolite which appears in the spectrum band is 2.4 diaminotoluene, considered to be derived from the polyisocyanate segments of PU.

Akutsu et al. ${ }^{[11]}$ utilized a polyurethane degradation enzyme, a PU esterase, derived from Comamonas acidovorans TB-35. This enzyme degraded solid polyester PU, obtaining the metabolites diethylene glycol and adipic acid. The results obtained in this study indicate that the PU esterase enzyme degraded the PU in two stages: hydrophylic adsorption on the surface of the PU and hydrolysis of ester chains.

Howard \& Blake ${ }^{[12]}$ studied the growth of Pseudomonas fluorescens in PU polyester, during the purification and characterization of the enzyme polyurethane protease.

Santos et al ${ }^{[13]}$ studied the biodegradation of polyurethane foam derived from caster oil. Thermogravimetry was utilized to study the behavior of this foam when inoculated with microrganisms present in leachate, in a biological degradation

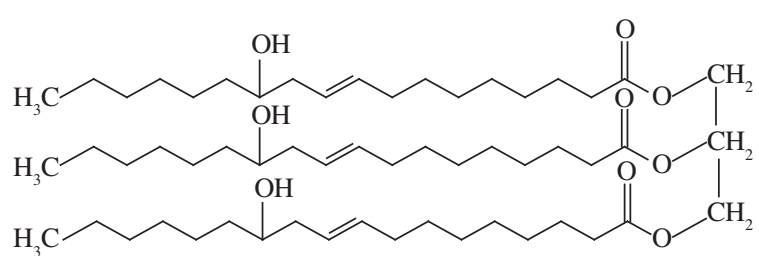

Figure 1. Structure of rincinoleic acid tryglyceride.

agent of grease and oils and in Aspergillus niger culture. The thermogravimetric curves confirmed biodegradation of the foam, showing variations in thermal behavior in the samples inoculated with microrganisms. The authors concluded that because this PU was of vegetable origin, the probable biodegradation mechanism was related to the process of fats degradation.

The Analytic Chemistry and Technology of Polymers Group from USP-São Carlos has developed a different kind of foam, made from castor oil, which is a raw material that is renewable and of natural origin: castor oil is a triglyceride derived from ricinoleic acid (Figure 1) and it is obtained from the seed of the plant "Ricinus Communis", which is found in tropical and subtropical places (abundant in Brazil). This foam is a practical alternative to traditional PUs ${ }^{[14]}$.

Due to the presence of ricinoleic acid, caster oil possesses singular chemical characteristics in comparison to the majority of vegetable oils. Ricinoleic acid presents the peculiarity of being one of the few acids whose natural chemical structure possesses three highly reactive functional groups: the hydroxyl group in the $12^{\text {th }}$ carbon, unsaturation in the $9^{\text {th }}$ carbon and the carbonyl group in the 1 st carbon. Polyester polyol, the raw material for the synthesis of polyurethanes can be obtained from ricinoleic acid.

The aim of this research was to study the biodegradation of this foam by using microorganism cultures, originating from biological agents that are able to degrade grease. The biodegradation process of the foam was analyzed through solid media agar-plate tests, where the occurrence of clear zones in turbid plates indicates the degradation of polymer particles surrounding the colonies.

\section{Materials and Methods}

Microorganisms: The microorganisms used in the tests were taken from a commercially available biological agent used for the degradation of greases, produced by Biobac Biotecnologia Indústria e Comércio Ltda., as follows:

- Aspergillus sp., species not yet identified, named FUN1;

- Aspergillus sp., species not yet identified, named FUN5; and

- Chryseobacterium meningosepticum, named BAC1.

In the Literature, it is common to encounter studies where the microorganisms of the genus Aspergillus are utilized in the biodegradation of organic compounds. Ueta et al. ${ }^{[15]}$ utilized Aspergillus fumigatus in biodegradation tests of the 
herbicide atrazine. Pereira \& Lemos $^{[16]}$ utilized Aspergillus versicolor in a study of the biodegradation of soils impacted by petroleum spills, seeking to increase the scale of static bioreactors. Silva et al. ${ }^{[17]}$ developed a biodegradation study of agricultural residues as an alternative to reduce environmental risks in the semi-arid region of Sergipe, utilizing Aspergillus terreus, Aspergillus oryzae and Aspergillus niger microorganisms. Rosa et al. ${ }^{[18]}$ studied the biodegradability of PCL and PHB in a fungi pool which included Aspergillus niger.

In the case of bacteria, the recent work of Lors et al. ${ }^{[19]}$ that utilized a "pool" de microorganisms, including bacteria of the genus Chryseobacterium, in the biodegradation of aromatic Polycyclic aromatic hydrocarbons can be cited.

Isolation of microorganisms: The microorganisms were cultivated in a $30{ }^{\circ} \mathrm{C}$ plate, being the fungus in a Saboraud solid-media, with the following composition (per liter): dextrose, $40 \mathrm{~g}$; agar, $17 \mathrm{~g}$; the bacteria were cultivated in an agar nutrient media, with the following composition (per liter): meat extract, $3 \mathrm{~g}$; peptone, $5 \mathrm{~g}$; agar, $17 \mathrm{~g}$. Plates with isolated colonies of the cited microorganisms in their respective agar cultures are shown in Figure 2.

A method of surface sowing, with the help of a Drigalski handle, was used. In this technique, a diluted drop of the sample is placed on the surface of the agar, and spread over the surface using an inoculating hook. The objective is to decrease the microbe population so that there will be enough space between the individual cells so that the individual cells will produce a colony that is not in contact with the other colonies. To isolate a pure culture, an individual colony is transferred from the medium to a test tube. After isolation, the microorganism should be in a pure culture where all the cells in the population should be identical in the sense that they originated from the same parent cell ${ }^{[20]}$.

The identification of the microorganisms was made by the staff of Prof. Dr. Carlos Henrique G. Martins, of the Laboratory of Microbiological Research at UNIFRAN (University of Franca). According to the laboratory report, these microorganisms are not pathologenic.

Clear-zone test: The halo zone technique has been used in various studies on biodegradation of polymers. This technique consists of the utilization of plates with a solid agar medium which makes it possible to evaluate the biodegradation of polymers of specific strains of microorganisms, because the activity of the enzymes produced permits the visualization of transparent halos. The halos formed are distinct, circular and reproducible, indicating the degradation of polymer particles surrounding the microorganism colonies. In the present study, the halo zone technique was utilized for the following objectives:

- To prove that polyurethane foam obtained from vegetable oils is biodegradable; and

- To identify which of the microorganisms extracted from the biological agent Bacgor, are capable of promoting degradation of polyurethane foam.

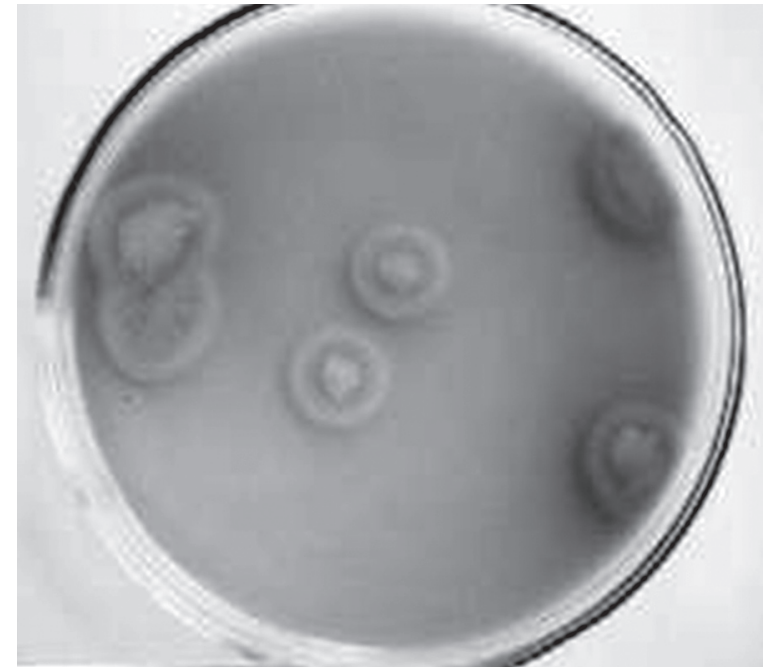

(a)

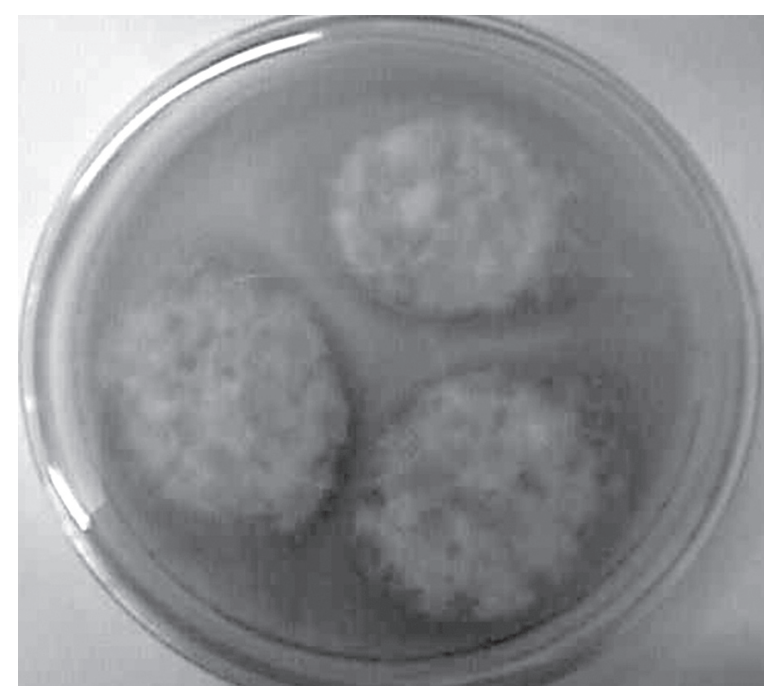

(b)

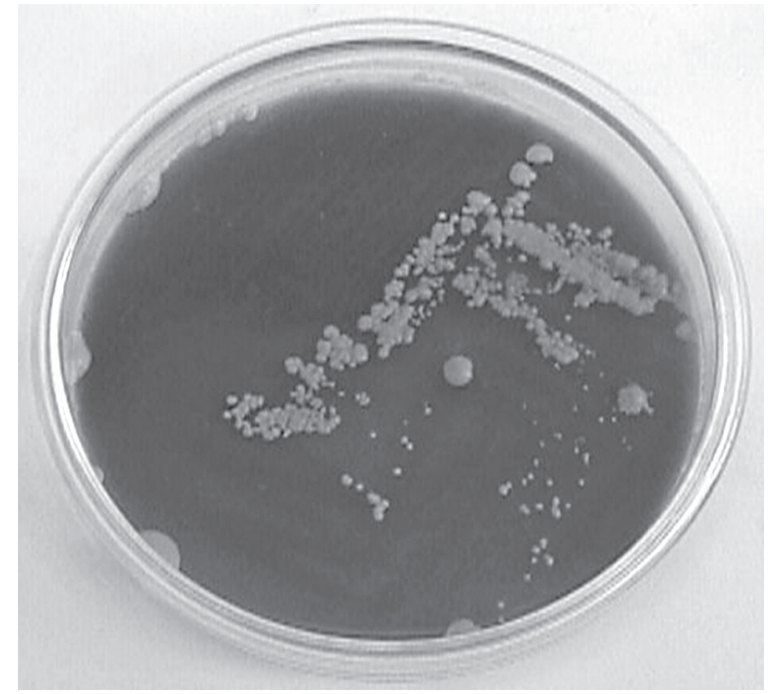

(c)

Figure 2. Plates with isolated colonies: a) FUN1: Aspergillus sp.; b) FUN5: Aspergillus sp.; and c) BAC1: Chryseobacterium meningosepticum. 
Ground polymer samples were mixed with culture medium in liquid state to form, after cooling, a solid medium. The inoculation was made at two points in the medium by point technique and the duration of the experiment was 216 hours.

This method was chosen because it offered a measurable quantitative criteria as well as being relatively fast and inexpensive. The transparent halo zones did not necessarily indicate complete utilization of the compound, just the possible breaking of the polymeric chain as a decisive stage of degradation.

Augusta et al. ${ }^{[21]}$, studied the biodegradation of poly (3-Hydroxyalkanoates), concluding that the formation of halo zones and therefore, the biodegradation of polymer particles, depended certain requirements. The microorganisms should excrete enzymes that, when mixed into the medium, would interact with the polymer. Aside from this, the rate of the zone of growth $\left(\mu_{\mathrm{A}}\right)$ depends on the quantity of enzymes produced by the microorganisms as well as the activity of these enzymes. Thus, the halo zone technique makes it possible to accompany the ability of each microorganism to degrade polymers as well as the degradation of the materials.

Foster et al. ${ }^{[22]}$ utilized the halo zone technique in a quantitative form in that the degradation was expressed in terms of loss of polymer mass over time. This technique was utilized

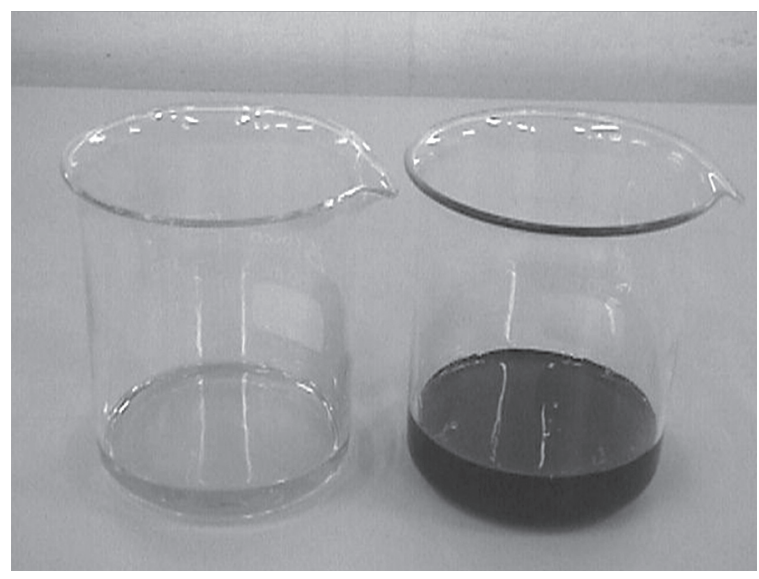

(a)

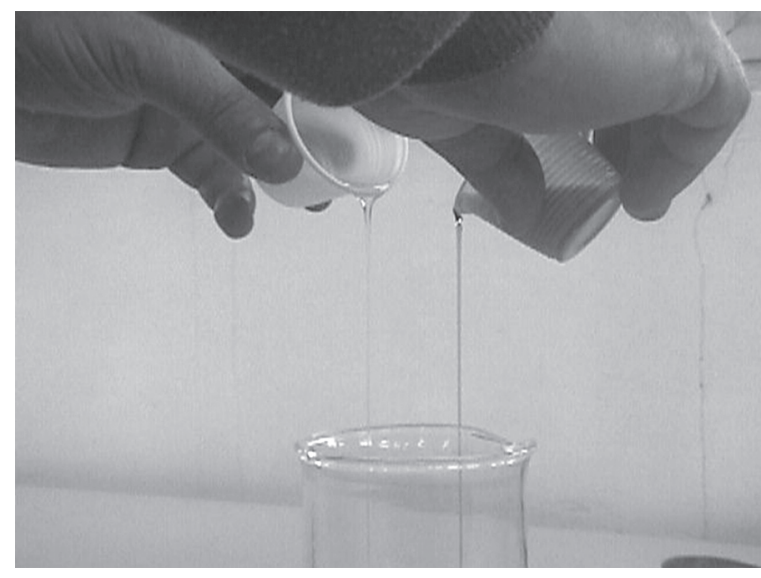

(b) to investigate an extracellular depolymerase of Pseudomonas maculicola.

According to Pranamuda \& Tokiwa ${ }^{[23]}$, who conducted studies on the degradability of plastics containing PLA (poly L-lactide acid), the formation of a halo surrounding the colony indicates the solubility of the polymers by the secreted enzymes.

Solid-media for clear-zone tests: For tests with bacteria, a mineral salt media with the following composition was used (per liter): $\mathrm{KH}_{2} \mathrm{PO}_{4}, 0.7 \mathrm{~g} ; \mathrm{K}_{2} \mathrm{HPO}_{s}, 0.7 \mathrm{~g} ; \mathrm{MgSO}_{4} \cdot 7 \mathrm{H}_{2} \mathrm{O}$, $0.7 \mathrm{~g} ; \mathrm{NH}_{4} \mathrm{NO}_{3}, 1.0 \mathrm{~g} ; \mathrm{NaCl}, 0.005 \mathrm{~g} ; \mathrm{FeSO}_{4} .7 \mathrm{H}_{2} \mathrm{O}, 0.002 \mathrm{~g}$; $\mathrm{ZnSO}_{4} .7 \mathrm{H}_{2} \mathrm{O}, 0.002 \mathrm{~g} ; \mathrm{MnSO}_{4}, 0.001 \mathrm{~g}$; agar, $20 \mathrm{~g}$; polymer, $6 \mathrm{~g}$. The $\mathrm{pH}$ was adjusted to 7.0 at $25^{\circ} \mathrm{C}$. For tests with fungus, a media with the following composition was used (per liter): $\mathrm{NaNO}_{3}, 2.0 \mathrm{~g} ; \mathrm{KHPO}_{4}, 0.7 \mathrm{~g} ; \mathrm{K}_{2} \mathrm{HPO}_{4}, 0.3 \mathrm{~g} ; \mathrm{KCl}$, $0.5 \mathrm{~g} ; \mathrm{MgSO}_{4} \cdot 7 \mathrm{H}_{2} \mathrm{O}, 0.5 \mathrm{~g} ; \mathrm{FeSO}_{4} \cdot 7 \mathrm{H}_{2} \mathrm{O}, 0.01 \mathrm{~g}$; agar, $20 \mathrm{~g}$; polymer, $6 \mathrm{~g}$; and thiamine hydrochloride, $0.1 \mathrm{ppm}$. The $\mathrm{pH}$ was adjusted to 6.0 at $25^{\circ} \mathrm{C}$.

Polymeric material: For this research, a natural polyurethane foam derived from castor oil, produced by the Group of Analytic Chemistry and Technology of Polymers from USP-São Carlos and also synthetic commercial foam, produced by Indústria e Comércio Santa Maria Ltda. Figure 3 shows a synthesis of polyurethane foam: the mixture of re-

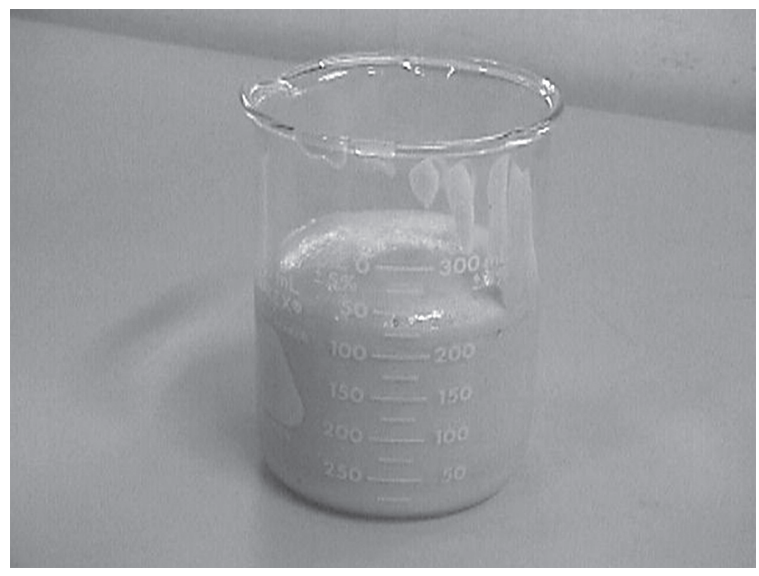

(c)

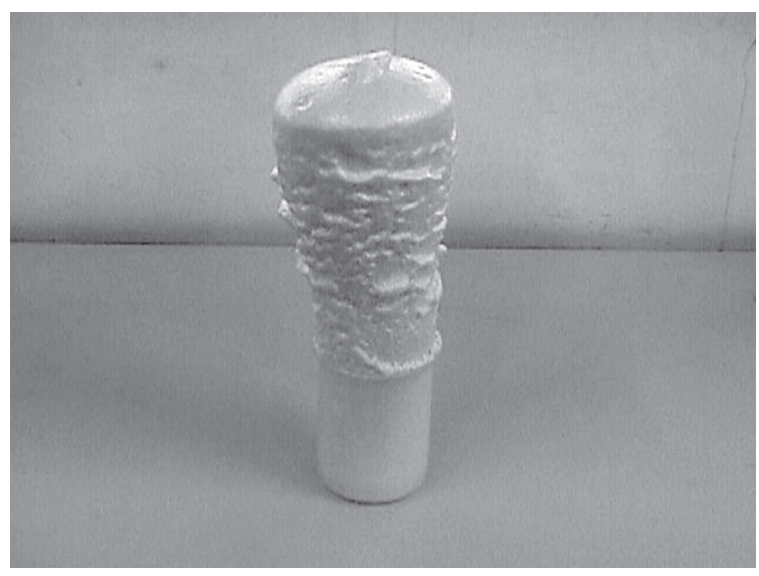

(d)

Figure 3. Sages of polyurethane synthesis: a) polyol and pre-polymer; b) during mixing; c) beginnining of foam formation; and d) completed foam product. 
agents with the reaction of the formation of polyurethane, which rises due to the gas released by the reactive medium.

Preparation of the plates: The plates were prepared with solid-media for tests with clear-zones mentioned above. The polyurethane foams were transformed in powder by using emery, and autoclaved with the media. Thus, the polymer becomes the only source of carbon in the life cycle of the microorganisms. Inoculation of the plates was carried out by plate puncturing.

Measurement: The radius of the zone and degradation was measured each 24 hours, and the numbers used in the graphic were the mean of the results of four different samples. The superficial area of the zone is similar to the area of a circumference with a radium $r$. The hypothesis for the production of the zone growing modeling is the following: the growth of the halos maintain a uniform radius throughout the theta $(\theta)$ for each time interval:

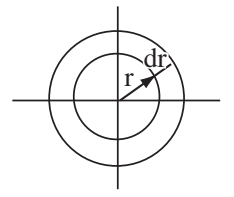

The growing zone rate $\left(\mu_{\mathrm{A}}\right)$ is defined as a variation of the clear-zone area (A), time (t) and area $\pi r^{2}$ :

$$
\mu_{A}=\frac{d A}{d t}=\frac{2 \pi r d r}{d t}
$$

The growing rates reach a maximum area in a minimum period of time when the second derivative is equal to zero:

$$
\mu_{A} \rightarrow \mu_{\text {max }} \text { where } \frac{d A^{2}}{d t^{2}}=0
$$

We approximated the first derivative with rates of the differences $(\Delta)$, and considered the maximum inclination of the curves:

$$
\mu_{A}=\frac{d A}{d t} \cong \frac{\Delta A}{\Delta t} \text { and } \rightarrow \mu_{\max }=\frac{A_{t 2}-A_{t 1}}{t_{2}-t_{1}}
$$

The time limits considered were: $\mathrm{t}_{1}=96$ hours and $\mathrm{t}_{2}=120$ hours; in the corresponding curves there was a steeper inclination of the curves.

\section{Results and Discussions}

The experiments were made by using different polymers and different microorganisms. Thus, we could observe different properties concerning the degradation of a polymer made from a natural product in relation to a synthetic polymer, as the microorganism degradation differed in accordance with the different degradation factors of the polymers. The results are shown in Figure 4.

Note that as time passes, the halo increases until approximately 168 hours, when stabilization begins to occur. This stabilization must be related to the decrease in a determinate organic function of the foam that the microorganism can easily consume ${ }^{[21]}$.

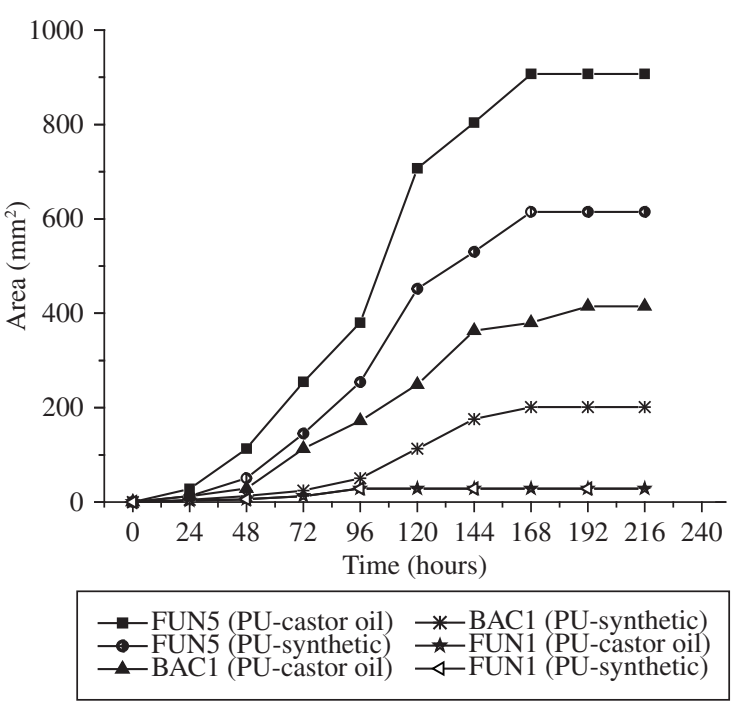

Figure 4. Formation of clear zones in polyurethane foam samples derived from castor oil and synthetic polyurethane, after biodegradation process.

Table 1. Growing zones rates: $\mu_{\text {maxx }}\left(\mathrm{mm}^{2} / \mathrm{h}\right)$.

\begin{tabular}{cccc}
\hline \multirow{2}{*}{ Polymers } & \multicolumn{3}{c}{ Microorganisms } \\
\cline { 2 - 4 } & $\begin{array}{c}\text { Bacillus } \\
\text { cereus }\end{array}$ & $\begin{array}{c}\text { Gongronella } \\
\text { loutleri }\end{array}$ & FUN6 \\
\hline Castor oil polyurethane & 0 & 13.5 & 3.2 \\
Synthetic polyurethane & 0 & 8.2 & 2.6 \\
\hline
\end{tabular}

After 24 hours, the capacity each microorganism has to degrade foam can be distinguished because of the significant changes in the inclination of the curve. The microorganisms FUN5 presents maximum degradation in comparison to BAC1 and FUN1. In the case of FUN1, a smaller halo is presented and stabilizes after 96 hours. Aside from this, the rates of halo growth presented in Table 1 show that PU-vegetable foam presented a higher rate of biodegradation than petroleum PU foam, because the time interval is between 96 to 120 hours, at which the curves present their steepest angles.

Observing the values of $\mu_{\max }$ in Table 1, the microorganism FUN5 presents the best results, followed by BAC1. In the case of FUN1, as this presents a stable halo within the time interval studies, the value of the growth rate is equal to zero for both vegetable PU and petroleum PU, which makes both curves trace the same line.

\section{Conclusions}

Polyurethane foam of vegetable origin undergoes biodegradation in the presence of microorganisms through the biological agents supplied by Biobac Biotecnologia Indústria e Comércio Ltda., utilized for the degradation of grease. Due to its vegetable origin, the probable biodegradation mechanism for this PU foam would be related to the same degradation process as fats.

The same experiments were conducted with petroleum PU foam, produced commercially as sponges for household cleaning and mattresses, among other uses. In the tests con- 
ducted, this foam presented a biodegradation response that was inferior to that presented by foam of vegetable origin.

Utilizing the same microorganisms cited in a study by Cangemi et al. ${ }^{[24]}$ accompanied the biodegradation process of polyurethane foams utilizing the techniques of Scanning Electron Microscopy (SEM), thermogravimetry (TG) and Fourier- transform infrared spectroscopy with an accessory for attenuated total reflectance (FTIR-ATR). The results suggest that the degradation of polyurethane derived from castor oil occurs. TG curves are used in order to indicate the biodegradation, showing changes between the thermal behavior of the samples that were inoculated with microorganisms and the control samples. In the FTIR-ATR spectra, there are detectable changes between the spectra of control and attacked specimens; this suggests that degradation occurs at the decreased intensity of the absorption band at $1042 \mathrm{~cm}^{-1}$, corresponding to the esters links.

It is important to note that the chemical structure of foam derived from castor oil becomes susceptible to microorganism attack and can be considered a polymer with biodegradable characteristics, which is not the case for petroleum PU foam. Hopefully, this study has been another step in advancement of biodegradable plastics that may allow us to live more harmoniously with our environment in the future.

\section{Acknowledgements}

To CAPES, to Prof. Dr. Carlos Henrique Gomes Martins (UNIFRAN, Laboratório de Pesquisas Microbiológicas), who identified some of the microorganisms used in this research, and to Luiz Orlando Rosário (Biochemistry and Microbiology Department, UNESP - Rio Claro), for his technical support.

\section{References}

1. Souza, J. P. \& Lopes, J. C. - Plástico Moderno, 230, p.15 (1993).

2. Kelen, T. - "Polymer Degradation", Van Nostrand Reinhold Company, New York (1983).

3. Maddever, W. J. \& Chapman, G. M. - Plastics Engineering, 31, p.31 (1989).

4. Vilar, W. D. - "Química e Tecnologia dos Poliuretanos", Vilar Consultoria Técnica Ltda., Rio de Janeiro (2002).

5. Darby, R. T. \& Kaplan, A. M. - Journal of Applied Microbiology, 16, p.900 (1968).

6. Huang, S. J.; Macri, C.; Roby, M.; Benedict, C. \& Cameron, J. A. - "Biodegradation of polyurethanes derived from polycaprolactanodiols" in: Urethane Chemistry and Applications, Edwards, K. N. (Ed.), American Chemical Society, Washington, DC (1981).

7. Nakajima-Kambe, T.; Onuma, F.; Kimpara, N. \& Nakahara, N. - FEMS Microbiology Letters, 129, p.39 (1995).

8. El-Sayed, A. H. M. M.; Mahmoud, W. M.; Davis, E. M. \& Coughlin, R. W. - International Biodeterioration \& Biodegradation, 37, p.69 (1996).
9. Kim, Y. D. \& Kim, S. C. - Polymer Degradation and Stability, 62, p.343 (1997).

10. Nakajima-Kambe, T.; Onuma, F.; Akutsu, Y. \& Nakahara, T. - Journal of Fermentation and Bioengineering, 83, p.456 (1997).

11. Akutsu, Y.; Nakajima-Kambe, T.; Nomura, N. \& Nakahara, T. - Applied and Environmental Microbiology, 64, p.62 (1998).

12. Howard, G. T. \& Blake, R. C. - International Biodeterioration \& Biodegradation, 42, p.213 (1998).

13. Santos, A. M.; Claro Neto, S.; Chierice, G. O. \& Rodriges, M. L. B. O. - "Biodegradação de polímeros de poliuretano", in: Anais da $2^{\text {a }}$ Reunião Nacional de Microbiologia Aplicada ao Meio Ambiente, p. 52, Florianópolis - SC, (1998).

14. Cangemi, J. M.; Santos, A. M. \& Claro Neto, S. - Química Nova na Escola, 22, p. 17 (2005).

15. Ueta, J; Pereira, N. L.; Shuhama, I. K. \& Cerdeira, A. L. - Biodegradação de herbicidas e biorremediação por microrganismos degradadores do herbicida atrazina. Disponível em: <http:// www.rsa.ind.br/midia/ biodegrada\%E7\%E30_biorremedia\%E7\%E30.pdf>. Acesso em: 21 set. 2005.

16. Pereira, L. T. C. \& Lemos, J. L. S. - Ampliação de escala da biodegradação de petróleo por Aspergillus versicolor. Disponível em: <http: //ww.cetem.gov.br/publicacao /serie_anais_XII_Jic_2004/19Atigo\%20Jic\%20 2004\%20Leonardo\%20Tupi\%20e20Judith\%20lilianapdf>. Acesso em: 21 set. 2005.

17. Silva, M. A.; Melo e Souza, R. \& Souza, R. R. - Biodegradação de resíduos agrícolas como alternativa à redução de riscos ambientais no semi-árido sergipano. Disponível em: <http: //www.anppas.org.br/encontro/ segundo/papers/GT/GTOS/Silva_ma_e_outros.pdf>. Acesso em: 21 set. 2005.

18. Rosa, D. S.; Penteado, D. F. \& Calil, M. R. - Revista de Ciência e Tecnologia, 15, p. 75 (2000).

19. Lors, C.; Mossmann, J. R. \& Barbé, P. - Polycyclic Aromatic compounds, 24, p. 21 (2004).

20. Pelczar Jr., M. J.; Chan, E. C. S. \& Krieg, N. R. - "Microbiologia: conceitos e aplicações", Makron Books do Brasil Ltda., São Paulo (1997).

21. Augusta J.; Muller R. J. \& Widdecke H. - Applied Microbiology Biotechnology, 39, p. 673 (1993).

22. Foster, L. J. R.; Zervas, S. J.; Lenz, R. W. \& Fuller, R. C. - Biodegradation, 6, p. 67 (1995).

23. Pranamuda, H. \& Tokiwa, Y. - Biotechnology Letters, 21, p. 901 (1999).

24. Cangemi, J. M.; Santos, A. M.; Claro Neto, S. \& Chierice, G. O. - Polímeros, Ciência e Tecnologia, 16, p. 129 (2006).

Enviado: $21 / 10 / 07$

Reenviado: 15/01/08

Aceito: 18/01/08 